\title{
Design on Music Teaching System Based on J2EE
}

\author{
Zhe $\mathrm{Li}^{1, \mathrm{a}}$, Hui Ma ${ }^{2, \mathrm{~b}}$ \\ ${ }^{1}$ College of International Exchange, Bohai University, Jinzhou, 121013, China \\ ${ }^{2}$ School of Mathematics and Physics, Bohai University, Jinzhou, 121013, China \\ a503412508@qq.com, bhuima2016@163.com
}

Keywords: J2EE; music; teaching system; Spring; database design

\begin{abstract}
With the rapid development of the network and the growing maturity of the related teaching software, music teaching system as an aid teaching methods is the development trend of university music education. This paper designs the music teaching system based on J2EE. First, studies the key technologies required for systems, including J2EE, Spring framework; then, describes the main function of music teaching system, designs the system architecture; Finally, the database design, expounds information of the main table in detail; the contents of this paper to make music teaching more intuitive, concrete and image, enhance students' learning efficiency, is great significance to improve the level of music teaching.
\end{abstract}

\section{Introduction}

With the development of information network technology, the traditional teaching mode of teachers, classrooms, books for the center cannot meet the needs of the information society, and computer teaching based on the network as a modern educational technology is a profound impact on education. Computer teaching based on web is to use web as a teaching medium conveying the teaching content, the implementation of online teaching, teaching management, and online testing and online communication, promote the full communication between teachers and students, and helps to improve the quality of teaching, promote students' cognitive ability [1].

Music education is an integral part of education, it is quality education to really implement a comprehensive development of human as the goal, and to cultivate students' comprehensive ability is a key part. New "music curriculum standard" proposed, music education should embody the aesthetic value and creative development value, performance and social communication value and other's concept [2], to achieve these goals will depend on research and development of music teaching theory and practice, music teaching system design theory is the theory and practice of music teaching communication bridge. This paper is based on the "music curriculum standard" to carry on system design of the music curriculum content, it changes single teaching mode in the past traditional music class, for learners to provide rich and colorful graphics, audio and video, human-computer interaction three-dimensional teaching interface, easy to stimulate students' interest in learning. Music teaching system provides unlimited music teaching resources that can provide comprehensive, massive music knowledge and musical works information, further enriching the music teaching content, available to students in terms of in-depth study musicology as a comprehensive, detailed reference, improve teaching and learning efficiency, save a lot of time and energy access to information, reducing the burden of student learning.

\section{The Key Technology}

J2EE (Java2 Platform Enterprise Edition) is a system architecture of enterprise application which is proposed by SUN company, is a multi-layered, end to end solution. It provides a intermediate layer integrated framework to meet the high availability, high reliability, high scalability and low cost and other's demand, use Java2 technology to simplify the related complex issues of many enterprise solutions development, deployment and management[3]. Providing a unified development platform, reducing the complexity of developing multi-tier system, and the existing application provides 
strong support. The specific performance of these supports are: full support for EJB and good support for package and deploy applications, Support for adding directories and support for security mechanisms and the like. Due to the core of J2EE technology is Java2 platform, so it not only inherits the advantages Java2 platform, such as: platform independence, security, and so on, and an increase of a set of core enterprise application programming interface, all of which are standard modular components, including: Servlets, EJB, JSP, JDBC, RM1/CORBA and others[4].

J2EE core technology is the application program interface (API), a rich service (Service) and basic agreement formed the J2EE platform. Enterprise Java Bean (EJB), which defines a defined component, can be repeated-EnterpriseBeans. Software developers use these components as building blocks. In assembling the components, all Enterprise Beans need to build in the EJB server. Java Server Pages (JSP): it is a kind of dynamic HTML pages and user interaction technology, analysis in this angle, can find it is very similar to PHP and Microsoft ASP and other dynamic web development technology, in the program dynamic load and run time, its main operational sequence is first JSP converted to Servlet, then analyze and resolve the basic form of the Servlet, compile it. Java Servlet: Servlet is a small Java program that is CGI technology of Java platform, which extends the Web server's functionality, quickly create a dynamic interactive user interface, and a general comparison of traditional CGI can see out, Java Servlet has higher efficiency and easier to use[5]. Servlet is a dynamically loaded module, providing services for the Web request from students, teachers and administrators. JSP is compiled into byte code before execution. The byte code is executed by the Java virtual machine, which is managed by the Servlet engine. All of the JSP files are converted to Servlet to run. Therefore, in the process of system implementation, the implementation of the Servlet engine is a key.

Spring is a lightweight framework, which is extracted from the actual development, and provides a lightweight solution. The solution includes core mechanism based on dependency injection, declarative transaction management based on AOP, and the integration of multiple persistent layer techniques, as well as the excellent Web MVC framework. Spring is committed to the solution of the J2EE application each layer, through the presentation layer, business layer and persistence layer [6]. Spring is a high degree of development and seamless integration with the existing framework. Spring framework is independent of all kinds of application server, based on the application of Spring framework, it can really achieve good performance of transplantation. Spring's DI mechanism reduces the complexity of business object replacement. Spring is highly open, and is not mandatory for applications that rely entirely on Spring, the developer is free to choose the part or all of the Spring framework. The Spring framework is shown in Fig. 1.

\begin{tabular}{|c|c|c|c|}
\hline \multirow{2}{*}{$\begin{array}{c}\text { Spring AOP } \\
\text { Source-level } \\
\text { metadata } \\
\text { AOP } \\
\text { infrastructure }\end{array}$} & $\begin{array}{c}\text { Spring ORM } \\
\text { Hibernate support } \\
\text { iBats support } \\
\text { JDO support } \\
\end{array}$ & \begin{tabular}{|c|} 
Spring Web \\
Web application content \\
Multipart resolver \\
Web utilities \\
\end{tabular} & \multirow{2}{*}{$\begin{array}{c}\text { Spring Web } \\
\text { MVC } \\
\text { Web MVC } \\
\text { framework } \\
\text { Web views } \\
\text { JSP/Velocity } \\
\text { PDF/Excel }\end{array}$} \\
\hline & $\begin{array}{c}\text { Spring DAO } \\
\text { JDBC support } \\
\text { DAO support } \\
\text { Transtraction infrastructure }\end{array}$ & $\begin{array}{c}\text { Spring Context } \\
\text { Application content } \\
\text { UI support } \\
\text { Validation } \\
\text { JNDI EJB and } \\
\text { remoting Mail } \\
\end{array}$ & \\
\hline \multicolumn{4}{|c|}{$\begin{array}{l}\text { Spring Core } \\
\text { Support utilities } \\
\text { Bean container }\end{array}$} \\
\hline
\end{tabular}

Fig .1. Spring framework diagram 


\section{Functional Structure Design}

Music teaching system mainly has three kinds of users: administrators, teachers and students. The functional authority of the three users is described as follows.

The functions of the administrator are mainly system user management, announcement management, teaching resource management and assistant teaching teacher, and so on. Among them, system user management, divided into the teacher and student information management, system settings management, log management and auxiliary decision-making management. Can increase, delete users, and view user information, set user permissions. Announcement management may be the teacher's announcement to carry out the audit, add, delete and so on. Resource management, including by teachers uploaded various learning resources and music video management, homework management, test questions library management, music knowledge management. Teaching management, the administrator needs to all classes and teachers, to make reasonable arrangements and deployment, in order to successfully complete the teaching plan.

Main function of teachers can upload and change the music curriculum-related information, including: course descriptions, syllabus, teaching plans, courseware video and other types of learning materials. Teachers can publish relevant information in the bulletin board of the course, including: class hours, the examination time, adjust class time, homework arrangements. Can add, delete, and modify music course teaching information, manage music basic knowledge module, musical common sense module, music appreciation module. Management of student homework, the online answer student questions, teachers can also be a comprehensive evaluation of students, and understand the relevant class information of students, according to the students' homework completion and test scores, obtained the evaluation data, teach students in accordance with their aptitude, and help students to improve learning and improve teaching quality.

The main function of the student are online learning, browse announcement, downloads, class homework answer, online discussions, score query. The most important module is online learning. Including learning music basic theory and knowledge, music common sense learning, music appreciation, student can upload the syllabus, teaching plans understand the teaching arrangement of music course, to guide their self-learning, while download the relevant learning information on after-class, self-learning. To do not understand the place, students can repeatedly watch videos, view data, and can be completed the teacher's homework online, as well as online testing [7-8].

\section{Architecture Design}

In the system design, committed teachers and students to easily complete the teaching activities, according to the system requirements analysis, development of the education system is an open, reconfigurable, scalable system. According to the architecture of the system and the idea of software design modular, the music teaching system using three-tier architecture design, the specific architecture is shown in Fig. 2. 


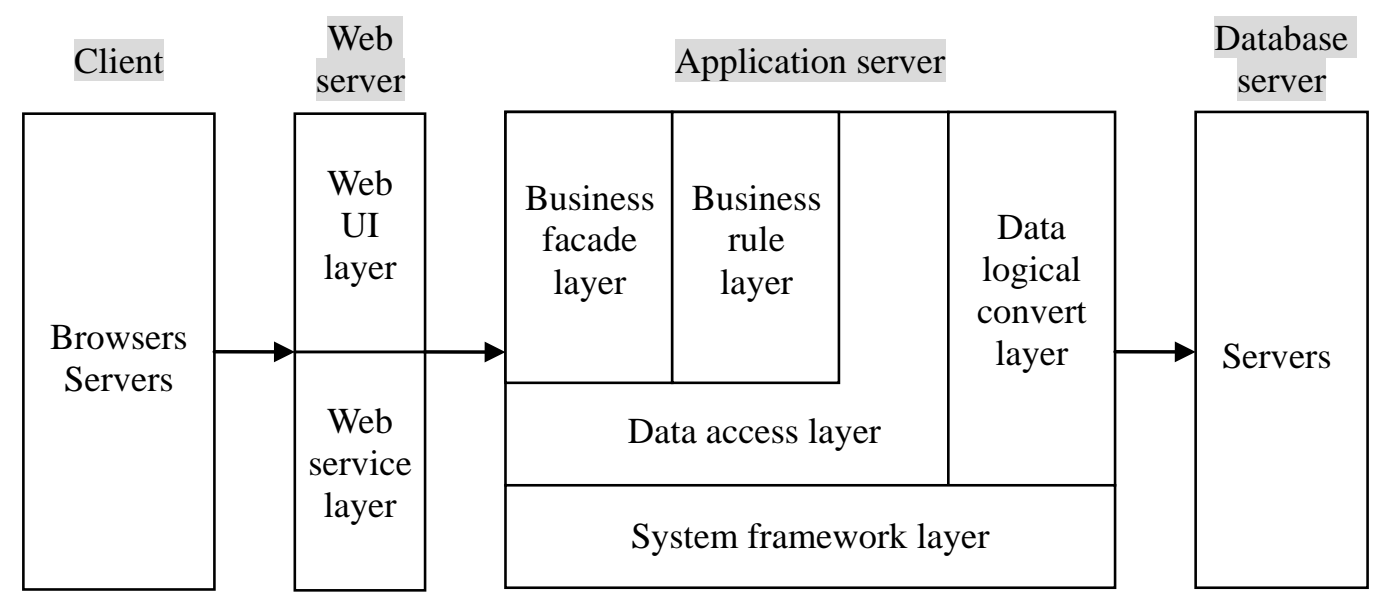

Fig .2. Architecture diagram

In Fig. 2, the architecture of the system is divided into Web Server layer (presentation layer), Application Serve layer (control layer) and Database Server (Data Access Layer) in three levels, in which the presentation layer consists of Web UI Layer and Web Service layer composed, mainly JSP and HTML pages, for receiving a user's request, return to the operating data, the use of JSP technology to achieve interaction with the client, is the entry of the application access [9]; control layer mainly use Spring and other core framework to complete, implement business logic processing of teaching system, the client sent service request by calling the data access layer for processing, and the processing result is displayed to the client in the specific form of user interaction, so that users viewing and browsing; data access layer mainly realizes the interaction between the business logic layer and the database, to prevent business requests from accessing the database directly, causing data inconsistency, to protect the safety and integrity of the data.

\section{Database Design}

To develop a Web-based database, the most important is the structural design of background database. The design principles must meet the needs of the entire system. This paper uses the relational database. The system uses the Server SQL to complete the database design.

The user needs to abstract the process of information structure (concept model). It is conceptual structure design. Its task is to define the data dictionary arising from demand analysis, database application operation tasks defined as the basis, determine the relationship between entities and entities within the system, with the E-R model and comprehensive relationship diagram to express information model of the system. The model objectives of conceptual design are: to establish a high level conceptual model that helps the user to understand and on a variety of database systems management implemented [10]. Conceptual design is the focus of the database design. It will be the user's data requirements clearly expressed. In the database design of the system, first from system analysis obtained the data storage in the data dictionary was to analyze, analyze the relationship between the various data stores, then in order to obtain the relationship mode of the system. After getting the data item and data structure, and design and meet the relationship between the various entities, then with E-R diagram, namely Entity-Relationship diagram will express these; lay the foundation for the logic structure design. E-R diagram shows methods of the entities, attributes and contact. In this system, the data of music basic theory knowledge query volume is most, it is one of the most typical E-R diagram is music basic theory learning module, as shown in Fig. 3, because the properties are more, the figure is listed the main attribute. 


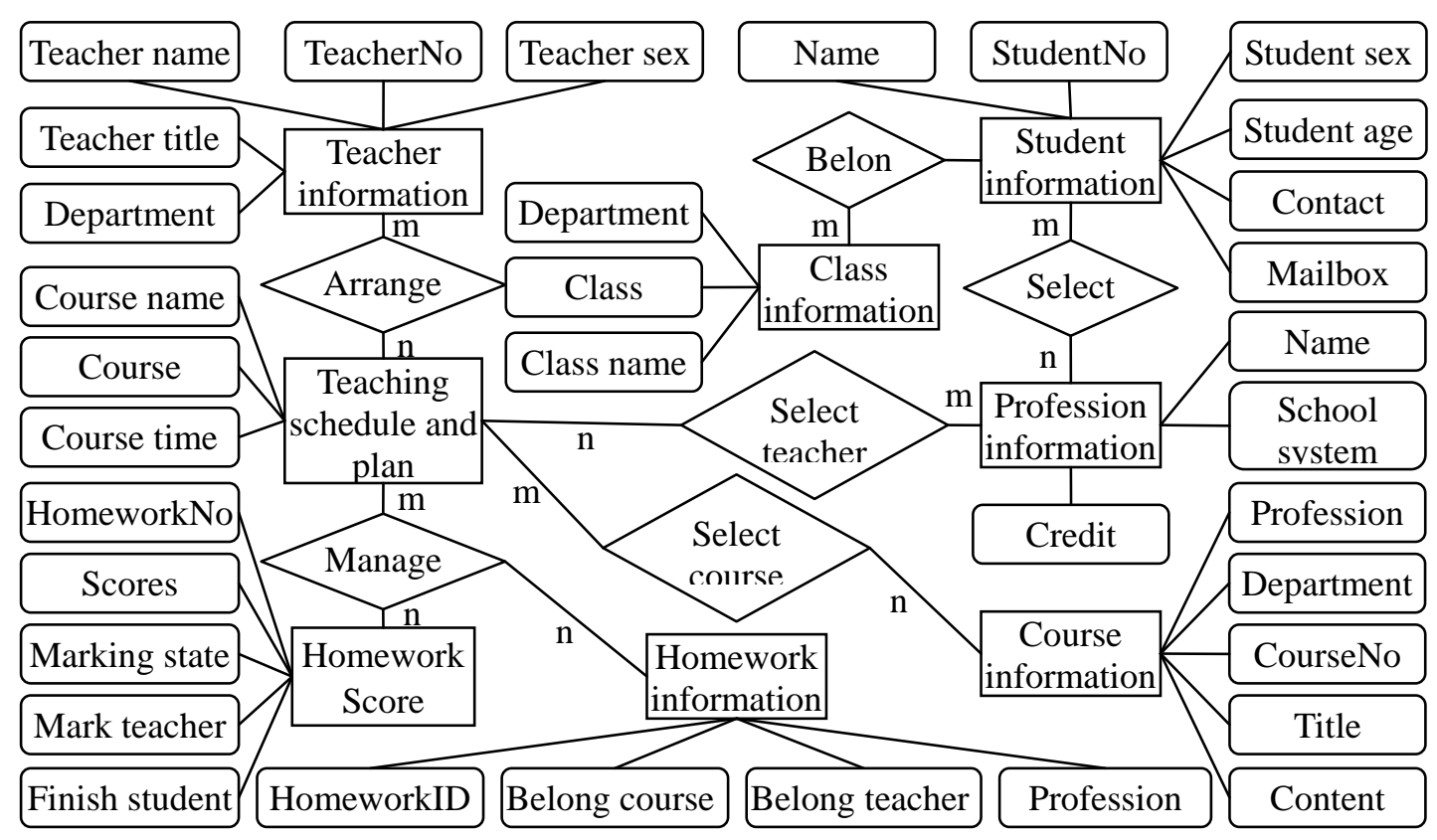

Fig .3. The E-R diagram of music basic theory learning module

Logical structure designed according to the conceptual structure design, system database in this article is a music database, including music basic theory knowledge information table, music common sense information table, music appreciation track information table, homework information table, teacher user information table, student user information table, administrator information table and so on. The main information table is described as follows.

Music basic theory (basic theoretical knowledge subject, number, content, source, file type, file size, modified date, relevant curriculum, teacher's name, address files, downloads, remark);

Music common sense (music common sense title, content, file type, file size, source, update date, relevant curriculum, teacher's name, address file, downloads, comments);

Music Appreciation track (track name, form, lyricist, composer, era, disk storage path, file size, file type, modified date, relevant courses, downloads);

Homework (the homework title, homework number, homework content, homework submitter, homework submission time, notes);

Student information (student number, name, password, gender, age, date of birth, department, professional, class, mail, telephone, score);

\section{Conclusion}

With the continuous development of technology, music teaching system is applied to music education represents a new teaching idea and teaching mode, it is requirement of modern education, it has become an indispensable teaching method, but also an important sign of education means to modernize and diversify. The music teaching is divided into music appreciation and theoretical teaching, music teaching system based on J2EE has rich resources, informative, vivid, interactive, with rich and vivid teaching resources, friendly man-machine interface and other advantages, which enriches the music teaching content, easy to stimulate students' interest in learning, so that students can get the fullest from the sensing materials, at the same time to their own learning real-time self-assessment, while improving the quality of teaching.

\section{References}

[1] X. Y. Duan, "Design and Implementation of Mobile Teaching Management System Based on OpenWrt," Master's degree of Xiamen University, 2014. 
[2]
Baidu
Library,
"Music
Curriculum
Standards," http://wenku.baidu.com/view/386e760416fc700abb68fc5e.html, 2015-7-20.

[3] Z. P. Ding, "Design and Implementation of Distance Teaching System Based on J2EE Structure," Computer \& Digital Engineering, vol. 39, no. 10, pp. 208-211, 2011.

[4] M. Cheng, "Design and Realization of Network Video Teaching System Based on J2EE," Master's degree of University of Electronic Science and Technology, 2013.

[5] D. Q. Bai, "Research and Design on Multi-terminal Oriented Integrated Teaching System," Master's degree of Dalian University of Technology, 2014.

[6] H. L. Hou, "Design and Implementation of Information Platform of Graduate School Based on J2EE," Master's degree of Dalian University of Technology, 2014.

[7] X. M. Peng, "Design and Implementation of Music Appreciation Teaching System Based on B/S Structure," Master's degree of Electronic Science and Technology University, 2011.

[8] C. Ma, "Based on Streaming Media Teaching System Design and Implementation," Master's degree of Electronic Science and Technology University, 2012.

[9] W. Hao, "Design of Music Teaching Aids Management System Based on J2EE," Master's degree of Electronic Science and Technology University, 2013.

[10] W. J. Su, "The Research and Design in The Secondary Vocational School Network Anxiliary Teaching system," Master's degree of South China University Technology, 2013. 